\section{Concepções e tipologia de conflitos entre trabalhadores e gerentes no contexto da atenção básica no Sistema Único de Saúde (SUS)}

\author{
Conceptions and typology of conflicts between \\ workers and managers in the context of primary \\ healthcare in the Brazilian Unified National \\ Health System (SUS)
}

\section{Concepciones y tipología de conflictos entre trabajadores y gerentes en el contexto de la atención básica en el Sistema Único de Salud (SUS)}

\author{
1 Departamento de Saúde \\ Coletiva, Universidade \\ Estadual de Londrina, \\ Londrina, Brasil. \\ 2 Escola de Enfermagem, \\ Universidade de São Paulo, \\ São Paulo, Brasil. \\ 3 Faculdade de Medicina \\ Universidade de São Paulo, \\ São Paulo, Brasil. \\ Correspondência \\ B. G. Carvalho \\ Departamento de Saúde \\ Coletiva, Universidade \\ Estadual de Londrina. \\ Rua Chile 43, Londrina, PR \\ 86010-220, Brasil. \\ brigidagimenez@gmail.com
}

\begin{abstract}
This study aimed to analyze perceptions of conflict between workers and managers in primary healthcare units and to present a typology of conflicts on the job. This was a comprehensive interpretive case study with a critical hermeneutic approach. Data collection techniques included: focus group with managers, workplace observation, and worker interviews, conducted from April to November 2011. The results were triangulated and indicated the coexistence of distinct concepts of conflict, typified in six modalities: lack of collaboration at work; disrespect resulting from asymmetrical relations between workers; problematic employee behavior; personal problems; asymmetry with other management levels; and inadequate work infrastructure. The relevance of (non)mutual recognition, as proposed by Axel Honneth, stood out in the interpretation of the causes and practical implications of these conflicts.
\end{abstract}

Patient Care Team; Management; Primary Health Care
Brígida Gimenez Carvalho 1

Marina Peduzzi 2

José Ricardo de Carvalho Mesquita Ayres 3

\section{Resumo}

Este estudo objetivou analisar percepções de conflito entre trabalhadores e gerentes de unidade básica de saúde e apresentar tipologia de conflitos vivenciados no trabalho. Trata-se de estudo de caso, de caráter compreensivo-interpretativo, de abordagem critica-hermenêutica. As técnicas de coleta foram: grupo focal com gerentes, observação do trabalho e entrevista com trabalhadores, realizadas de abril a novembro de 2011. Os resultados foram triangulados e apontam a convivência de distintas concepções de conflito. Foram tipificadas seis modalidades de conflitos, relacionados à falta de colaboração no trabalho; ao desrespeito decorrente de relações assimétricas entre trabalhadores; ao comportamento do funcionário-problema; aos problemas pessoais; à assimetria com outros níveis de gestão e à infraestrutura deficitária dos serviços. Destaca-se a relevância do (não) reconhecimento mútuo, na perspectiva proposta por Axel Honneth, na interpretação da gênese e implicações práticas desses conflitos.

Equipe de Assistência ao Paciente; Gerência; Atenção Primária à Saúde 


\section{Introdução}

O conflito constitui "característica intrínseca e inerradicável da vida organizacional" ${ }^{1}$ (p. 511), especialmente nas instituições em que os processos de trabalho são mediados, de forma imediata, pela interação social, como é o caso das organizações de saúde. Apresenta significados positivos ou negativos, dependendo de experiências anteriormente vivenciadas, mas também da estratégia utilizada para o seu enfrentamento 2.

O termo conflito vem do latim conflictus "bater junto, estar em desavença". Segundo Ferreira 3, significa: luta, enfrentamento; oposição entre duas ou mais partes; divergência de ideias, de opiniões.

Ao delimitar o conceito, Cecílio ${ }^{1}$ destaca que o conflito é sempre consciente e que sua eclosão e desenvolvimento ocorrem tanto por distintas posições que os atores envolvidos ocupam nas estruturas, como por intencionalidades opostas desses. Esse autor aponta que os conflitos se apresentam como fenômenos, fatos, comportamentos que, na vida organizacional, constituem-se em "ruídos", podendo ser observáveis (aqueles que exigem tomadas de providências do gestor) ou encobertos (aqueles que circulam nos bastidores e que, nos sistemas de gestão mais tradicionais, não conseguem ocupar a agenda da direção).

Empregado tanto na linguagem cotidiana quanto na linguagem especializada de diferentes disciplinas, como a Psicologia e as Ciências Sociais, que tratam os conflitos na interação social como tema de estudo, o termo conflito traduz uma situação de divergência, com a conotação de tensão, de violência, ou, pelo menos, de iminência de ruptura de um equilíbrio tornado precário 4.

A tensão e o rompimento da contratualidade se manifestam por meio do desrespeito, do desentendimento, da injúria e frequentemente envolve a dimensão emocional. Na vigência de um conflito, na maioria das vezes, afloram sentimentos negativos relacionados aos valores, crenças e percepções dos indivíduos na sua relação com o outro; decorrem também de experiências anteriores e trajetórias de vidas distintas 2 .

Apesar da relevância dessa temática para aqueles que exercem a função gerencial nos diversos espaços de atenção à saúde, a produção científica sobre a gestão do conflito entre trabalhadores em organizações de saúde é escassa, tanto em publicações de periódicos nacionais como internacionais, e ainda muito mais exígua aquela que trata do tema no espaço da atenção básica à saúde 5,6,7.

Com o intuito de ampliar a visibilidade e discussão do conflito nesse espaço, este estudo tem por objetivo analisar as percepções existentes sobre o conflito e apresentar uma tipologia de conflitos presentes na interação entre trabalhadores e gerentes no cotidiano do trabalho em unidades básicas de saúde (UBS), contribuindo, assim, para um melhor entendimento do tema.

\section{Referencial teórico}

Para a compreensão do fenômeno estudado, optou-se pela composição de um quadro teórico que engloba o referencial teórico do processo de trabalho em saúde 8, da teoria do agir comunicativo ${ }^{9}$ e da teoria do reconhecimento 10 .

A teoria do processo de trabalho em saúde foi aplicada, a partir dos estudos produzidos no Brasil por pesquisadores do campo da Saúde Coletiva $8,11,12,13,14$, para análise das práticas de saúde, com o intuito de elucidar características que acarretam a inserção desigual dos trabalhadores, em posições nucleares ou periféricas, na tomada de decisão e na produção do cuidado. $\mathrm{O}$ processo de trabalho em saúde, como exercício cotidiano, requer, por outro lado, interação e comunicação entre profissionais e usuários e entre os próprios profissionais, de modo que abarca não apenas uma racionalidade instrumental, do tipo meios-fins, mas também uma racionalidade comunicativa, que diz respeito à interação social. Para contemplar ambas dimensões das práticas de saúde, os estudos do processo de trabalho em saúde foram articulados 15 à teoria do agir comunicativo, de Jürgen Habermas.

No cotidiano do trabalho em saúde, nem sempre a interação entre os trabalhadores e entre esses e a gerência resulta em entendimento, sendo frequente a manifestação de conflitos. Em sua produção teórica, Habermas ${ }^{9}$, com base em uma aproximação dialética, em atitude crítica permanente, reconhece a presença de tensões e conflitos em interações nas quais um acordo normativo é problematizado e perturbado. No entanto, não aprofunda a análise da gênese dos conflitos nas organizações, questão considerada essencial neste estudo.

Para aprofundamento dessa questão, a abordagem sobre a gênese e manifestação do conflito está baseada na teoria do reconhecimento de Axel Honneth 10 e está pautada no entendimento de que o conflito não deve ser compreendido apenas como um participante operacional nas relações de poder, mas que, na sua ocorrência, estão implícitas exigências de reconhecimento recíproco, seja na esfera das relações interpessoais primárias, das relações jurídicas ou da estima social 16 .

Segundo Honneth 10, o conflito tem origem em experiências de ausência de reconhecimen- 
to, de desrespeito, vivenciadas em situações de interação. Para esse autor, o não reconhecimento pode acarretar diferentes formas de rebaixamento e ofensa dos sujeitos: maus-tratos e violação, na esfera das relações primárias; privação de direitos e exclusão, na esfera das relações jurídicas; e degradação e ofensa, na esfera da estima social. Para compreensão do "elo psíquico que conduz do mero sofrimento à ação ativa”, ou seja, o que leva um indivíduo a entrar num conflito, conclui que são as "reações emocionais negativas, como as que constituem a vergonha ou a ira, a vexação ou o desprezo; delas se compõem os sintomas psíquicos com base nos quais um sujeito é capaz de reconhecer que o reconhecimento social lhe é denegado de modo injustificado" 10 (p. 220).

Nesse sentido, este estudo procurou explorar o referencial de Axel Honneth 10 para produzir uma análise das relações intersubjetivas e das manifestações de conflito e assim compreender sua gênese e manifestação nos ambientes de trabalho em UBS.

\section{Metodologia}

Trata-se de um estudo qualitativo, de natureza compreensiva e interpretativa, desenvolvido por meio de um estudo de caso, único e integrado 17, ou seja, foi desenvolvido em um único município de médio porte, do norte do Paraná, Brasil, envolvendo mais de uma unidade de análise, nesse caso, mais de uma UBS. A opção pela realização do desenho do estudo de caso se deve ao interesse de investigar "um fenômeno contemporâneo em profundidade e em seu contexto de vida real, especialmente quando os limites entre o fenômeno e o contexto não estão claramente evidentes" 17 (p. 39), o que se aplica ao objeto deste estudo.

O município estudado possui 11 UBS, todas com a função gerencial instituída, e a atenção básica à saúde está organizada com base na Estratégia Saúde da Família, com cobertura populacional superior a $80 \%$. O processo de implantação dessa estratégia não se deu apenas com os servidores de carreira do município, e, à época da pesquisa, contava com trabalhadores com vínculo terceirizado, contratados por meio de Organização da Sociedade Civil de Interesse Público (OSCIP).

Os sujeitos da pesquisa foram os gerentes e demais trabalhadores das UBS. Os dados foram obtidos por meio de duas sessões de grupo focal, com os gerentes das 11 unidades; observação do cotidiano do trabalho em duas UBS e entrevista semiestruturada com 18 trabalhadores que atuavam nas UBS observadas, a saber: agentes comunitários de saúde (ACS), auxiliares adminis- trativos e de serviços, auxiliares de enfermagem, enfermeiros, dentistas, técnicos em saúde bucal e médicos. A coleta de dados foi realizada no período de abril a novembro de 2011.

Os registros da observação foram transcritos; as discussões dos grupos focais e entrevistas foram gravadas e, posteriormente, transcritas; e as gravações, após a transcrição em papel, foram inutilizadas. Os registros das falas foram editados quanto às correções gramaticais e, posteriormente, codificados para assegurar o anonimato dos participantes. Os gerentes foram codificados com a letra "G"; os coordenadores, com a letra "C"; e os trabalhadores, com a letra "T", seguida de um número, a saber: G1, [...], C1 [...] e T1 [...].

Para a análise do material empírico, primeiramente, foi realizada a conferência da fidelidade das transcrições, e, em seguida, a leitura flutuante dos registros dos dados para possibilitar a impregnação por seu conteúdo. Na sequência, foram feitas leituras repetidas e aprofundadas de cada grupo focal, de cada registro da observação e de cada uma das entrevistas, separadamente, a partir das quais foram constituídas sínteses - em que se procurou reconhecer as representações, as contradições e os antagonismos presentes em cada registro. A partir da leitura horizontal dessas sínteses iniciais, foram produzidas três novas sínteses, uma para cada conjunto de registros (grupos focais, observação e entrevistas), que foram cotejadas com os objetivos definidos para o estudo. Por último, seguiu-se uma análise transversal das sínteses, realizando-se, assim, a triangulação dos dados 18,19, evidenciando convergências e divergências, relações e contradições, o que possibilitou uma compreensão ampla e aprofundada do objeto de estudo.

Cabe destacar que a busca de compreensão e interpretação do texto e contexto desta pesquisa se pautou na hermenêutica crítica, como base conceitual de um caminho possível para um exame fundamentado e apreciação intersubjetiva do problema aqui tomado para estudo 20 .

Esta pesquisa respeita os preceitos éticos da Resolução no 466/2012 do Conselho Nacional de Saúde e foi aprovada pelo Comitê de Ética em Pesquisa da instituição na qual se insere um dos pesquisadores (no 971/2010). Também foi autorizada pelo gestor do município pesquisado e por todos aqueles que participaram diretamente na pesquisa.

A pesquisa foi apoiada financeiramente pelo Programa de Pesquisa para o SUS: Gestão Compartilhada em Saúde (PPSUS) / Fundação Araucária, na chamada de projetos 08/2009. 


\section{Resultados e discussão}

\section{Percepção do conflito}

Para os gerentes participantes do estudo, o conflito é visto como algo presente no exercício cotidiano do trabalho em todo serviço de saúde, pois, quando se "mexe com relações, é difícil dizer que você não lida com isso [conflito] no dia a dia. Então, é uma coisa que está sempre presente no nosso dia a dia de trabalho, os conflitos com a equipe" (G10). Não houve resistência dos gerentes em abordar o tema, pelo contrário, discutiram-no com naturalidade, como um fato cotidiano, que envolve tanto a relação entre funcionários como entre esses e os usuários. Apontaram que o enfrentamento dos conflitos é sempre tenso, e que não há um modo sistematizado de lidar com eles, apesar de ocorrerem cotidianamente.

Entre os demais trabalhadores, houve, inicialmente, maior resistência em abordar o tema, com algumas manifestações de negação de ocorrência do conflito no ambiente de trabalho. Nesse sentido, ao serem questionados sobre o tema, alguns referiram: "Nunca vi uma situação de desrespeito entre os trabalhadores” (T15) ou: "Conflito, conflito, graças a Deus, no nosso Posto não" (T3). No entanto, no decorrer das entrevistas, foi possível identificar concepções distintas sobre o conflito entre os trabalhadores.

A primeira concepção de conflito, mais genérica e abstrata, foi expressa por trabalhadores que ocupam uma posição mais nuclear no processo de trabalho em saúde, os profissionais médicos, para os quais o conflito raramente ocorre no trabalho, ou seja, "o que acontece são questões que existem dentro da convivência do humano, e entra muito na questão da educação de família, escolaridade etc. E, assim, um desrespeito declarado entre nós aqui é muito difícil falar, porque algumas coisas a gente pode não perceber, mas eu acho que são questões do próprio ser humano mesmo, onde tem ser humano tem conflitos..." (T1).

A segunda, expressa por trabalhadores que ocupam posição mais periférica nesse processo - os auxiliares de enfermagem e ACS -, mostra o reconhecimento da manifestação do conflito no cotidiano do trabalho e sua associação às divergências existentes entre os próprios trabalhadores, visto que pensam e se comprometem de forma distinta com os objetivos do trabalho conjunto. Segundo um desses trabalhadores, o conflito se dá nas relações, porque, entre eles, "cada um tem um pensamento diferente, então têm pessoas que arregaçam as mangas e trabalham em conjunto, têm outras que já se afastam [e dizem]: 'ah! eu não vou me envolver"' (T3).
Para esses, porém, o desrespeito nem sempre se manifesta diretamente, mas por meio de "brincadeiras de mau gosto, piadinhas, fofocas" (T13), “... [pela] indiferença, os olhares...” (T3).

As duas concepções manifestas expressam a inserção desigual dos diferentes trabalhadores no processo de trabalho em saúde, em particular de trabalhadores de nível superior e de nível técnico. Os primeiros ocupam posição nuclear e atuam em ambientes protegidos, com menor contato com outros profissionais, e o contato com usuários é intermediado por outros membros da equipe e escalonado em horários, o que explica, de certa forma, uma menor manifestação e uma percepção mais vaga de conflito. Já os segundos ocupam posição mais periférica, de menor valor social, em cujo processo de trabalho há contato direto com demais trabalhadores e com os usuários. Nessa posição, há pouco controle das variáveis existentes (quantidade de usuários que serão atendidos, motivo da procura dos usuários ao serviço, existência ou não de recursos para solucionar as necessidades dos usuários, autonomia do outro em participar ou não do processo de trabalho etc.), o que faz com que as relações estabelecidas, tanto com outros trabalhadores como com usuários, estejam mais suscetíveis a imprevistos, sendo mais frequente a ocorrência de conflitos.

Constata-se que a posição que os diferentes trabalhadores ocupam no processo de trabalho, mais nuclear ou periférica, faz com que vivenciem o ambiente de trabalho e as tensões presentes nesse espaço de maneira distinta, contribuindo para a existência de concepções também distintas sobre o conflito.

A análise do empírico possibilitou ainda compreender que o conflito é um fenômeno relacionado ao trabalho, imbricado ou permeado pela interação social, que se manifesta no contexto organizacional, dependendo do modo como e do quanto os diferentes trabalhadores se envolvem com o trabalho coletivo. Dessa forma, não são as relações humanas genéricas, abstratas, que estão em conflito, mas relações que se conformam concretamente nas interações constitutivas dos processos de trabalho. A emergência do conflito denota tensão ou mesmo rompimento dos regimes de validação normativos (referente ao mundo social) - indicando que os partícipes deixam de compartilhar as normas expressas do ponto de vista ético, moral e político; e/ou expressivo (referente ao mundo subjetivo), - rompem uma relação de confiança estabelecida entre eles, o que aponta para a possibilidade de questionamento, no mundo compartilhado, da vida 9 .

Na emergência dos conflitos, a tensão e o rompimento da contratualidade foram provo- 
cados por situações de desacordo e desrespeito, tanto na esfera das relações primárias como das relações jurídicas e ainda da estima social, frequentemente envolvendo a dimensão emocional e subjetiva, provocando, nos envolvidos, sentimentos de injustiça, de ira e vergonha 10 . Esses sentimentos tiveram potencialidade para desencadear um conflito, uma luta por reconhecimento.

\section{Tipologia dos conflitos}

A compreensão do conflito com base nas situações narradas e observadas no contexto do estudo e no quadro teórico adotado permitiu a elaboração de uma tipologia de conflitos manifestos na interação entre trabalhadores e gerentes de UBS.

Os quatro primeiros tipos de conflito estão afetos a aspectos microssociais, ou seja, a aspectos dinâmicos e relacionais do trabalho em saúde, relativos ao mundo da vida dos sujeitos pesquisados e estão relacionados: à falta de colaboração entre os trabalhadores, ao desrespeito decorrente de relações assimétricas entre os trabalhadores no ambiente de trabalho, ao comportamento do "funcionário-problema" e aos problemas pessoais.

Os dois últimos tipos de conflito se relacionam a aspectos macrossociais, considerados como aqueles processos sociais e históricos que se articulam ao contexto e nele adquirem uma conformação que se cristaliza e permanece inalterada por um dado período, tais como os aspectos mais sistêmicos da normatização, organização e funcionamento do Sistema Único de Saúde (SUS) como a assimetria com outros níveis de gestão e a infraestrutura e organização deficitárias dos serviços do SUS.

Neste estudo, o conflito tipificado como "falta de colaboração" foi o mais referido pelos trabalhadores e se manifestou tanto entre dois trabalhadores como entre dois grupos de diferentes turnos de trabalho. Sua origem se deu em função do não cumprimento de uma contratualidade prevista para a realização do trabalho coletivo, ou seja, se manifesta “...porque tem colega que trabalha, trabalha, trabalha, e outro colega que trabalha devagar [...] na minha visão é porque enrola. Aí sobrecarrega o outro..." (T17). Nesses casos, a falta de colaboração de um trabalhador ou um grupo deles fez com que os outros envolvidos se sentissem desrespeitados em suas contribuições, em seu valor social, ou seja, está afeto à esfera da estima social 7. Esse conflito aponta para o rompimento da contratualidade no plano normativo, em que as normas, do ponto de vista ético, moral e político, são colocadas em xeque; e também no expressivo - em que não se reconheceu os parceiros em interação como dignos de confiança, de sinceridade e autenticidade ${ }^{9}$. Cabe ressaltar que, nesses casos, a comunicação não foi utilizada em seu sentido forte, sendo perceptível que os sujeitos envolvidos na ação não alcançaram entendimento nem construíram acordos intersubjetivos válidos para que a contratualidade prevista para aquele espaço fosse preservada e/ou restaurada 9. Conflitos dessa natureza também foram relatados na atenção básica por outros autores 5,6,7.

O conflito tipificado como desrespeito " $d e$ corrente de relações assimétricas entre os trabalhadores" envolveu distintas categorias profissionais, em que os trabalhadores ou uma categoria desses (os trabalhadores terceirizados, em geral, e os ACS, em particular) não se sentiram reconhecidos pelos outros como pessoas de estima e de valor social enquanto integrantes da equipe de trabalho ${ }^{10}$.

Apesar de todos os trabalhos e trabalhadores serem necessários e importantes na unidade de saúde, cabe considerar que o conflito, nesse caso, reflete a quebra do regime de validade normativo; está relacionado à diversidade de vínculos $\mathrm{e}$ se deve ao descompasso e desencontro entre a contratualidade prevista e a socialidade vigente (no plano das práticas) de desigual valoração social dos trabalhadores de diferentes vinculações ao trabalho. A fala desse trabalhador é ilustrativa dessa questão: “...É que as auxiliares daqui parece que elas meio que humilham as ACS por elas serem ACS. Parece que elas são assim, tudo burro de carga. Não tem aquele respeito... É no jeito mesmo [de tratar] no dia a dia" (T10).

A esse respeito, Cecílio 21 (p. 549) aponta que a divisão social do trabalho resulta em tensões decorrentes das diferentes valorizações, como a remuneração e a correlação de poder entre os diferentes trabalhadores, "embora o trabalho de todos seja anunciado como igualmente imprescindivel para a 'finalização' do cuidado".

Constata-se que, no plano macrossocial, a divisão social e técnica do trabalho expressa a divisão social de classes, criando situações de desrespeito e diferenças entre os sujeitos que convivem no ambiente de trabalho, ou seja, o reconhecimento social no trabalho não é simétrico entre as categorias de trabalhadores. Simetria aqui não tem o significado de uma medida quantitativa destinada a medir o valor exato das contribuições dos envolvidos na relação. Pelo contrário, significa que todo sujeito tem a mesma chance de vivenciar o reconhecimento de suas capacidades e realizações como valiosas para a sociedade 10 .

Na discussão dos grupos focais, não foi feita referência pelos coordenadores a esse tipo de 
conflito. Cabe o questionamento: por que não houve o reconhecimento desse problema pelas coordenadoras? Será que não o percebem ou o ignoram porque não sabem lidar e/ou não dispõem de instrumentos para interferir nessa situação? Seja qual for o motivo, esse tipo de conflito não conseguiu acessar a agenda da gerência da instituição, ou seja, circula pelos bastidores e não tem força para se impor na agenda da direção, muito provavelmente porque atinge um grupo de trabalhadores com menor visibilidade e autoridade técnica, permanecendo, majoritariamente, como conflito encoberto ou latente 1 .

Ao analisar a origem desses conflitos, verifica-se que as formas "flexíveis" de contratação da força de trabalho têm, como consequência, o estabelecimento de vínculos mais tênues entre o trabalhador e a organização, acentuando-se o caráter transitório na relação de trabalho. Nas organizações públicas, em que prevalece o caráter do servidor estável, manifesta-se um contraste entre esses e os de contrato temporário, e o convívio de trabalhadores com diferentes formas de contrato gera tensões, latentes ou manifestas, produzindo, com certa frequência, uma hierarquia entre os "estáveis" e os "contratados" 22.

O terceiro tipo de conflito relacionado ao "funcionário-problema" foi referido tanto por trabalhadores como por coordenadores. É comum que o "funcionário-problema" provoque tensão ou conflito na relação com os outros trabalhadores da unidade - por não colaborar nas atividades de trabalho da unidade, por se recusar a desenvolver algumas atividades, ou pela má qualidade do trabalho executado -; com a gerência - por não haver respeito pela autoridade gerencial, pelo descumprimento das escalas e horário de trabalho e por restringir-se a fazer o que quer -; e também com usuários, tendo em vista o rompimento da contratualidade no que seria o núcleo da orientação do trabalho na atenção básica - o atendimento às necessidades de saúde dos usuários.

Está relacionado à postura e à atitude de alguns trabalhadores durante a execução do trabalho, comprometendo a funcionalidade da unidade. De forma geral, os "funcionários-problema” agem estrategicamente, há pouca escuta e vínculo com os usuários e há descumprimento da contratualidade prevista para com outros trabalhadores. Os funcionários denominados "funcionário-problema”, geralmente, são estatutários e têm estabilidade no emprego ou são aqueles que ocupam cargos por indicação política e, dessa forma, têm alguns privilégios e/ou proteção da gestão.

Nessa tipologia, verifica-se o descompasso entre dois sistemas jurídicos: o do direito indi- vidual de um segmento de trabalhadores - o estatuto do funcionário público -, e o do direito geral, constitucional - a normativa do SUS. Ou seja, há outro sistema que implica numa contratualidade que entra em confronto e extrapola o horizonte normativo do SUS, da atenção básica à saúde e das relações de trabalho. O "funcionárioproblema”, aquele que não faz, não cumpre suas atribuições, ampara-se e está respaldado num outro sistema jurídico, em que interesses outros, privados, competem com o interesse público, coletivo, como exemplificado na fala de um coordenador: “...ela colabora pouco, pois trabalha pouco e comparece pouco ao serviço. Atualmente, está de atestado por trinta dias e está gestante. [...] Já tinha colocado a mesma à disposição, porém, como ela falta muito, é mau negócio pra todo o mundo, então é uma coisa difícil. Ela tem uma carta que diz que ela só pode trabalhar sentada, que não pode ficar nervosa, que não pode fazer força, ou seja, graças a Deus, ela está de atestado [...] é insolúvel o problema" (C8).

Ressalta-se que a atuação no setor de saúde deve considerar que se trata de uma área em que o direito é imperativo, não se discute, é constitucional - a saúde é direito de todos (usuários) -, e há também o reconhecimento do direito trabalhista do trabalhador como justo e ético - remuneração justa, férias, previdência, estabilidade no emprego etc. No entanto, esses direitos dos trabalhadores do serviço público correspondem imediatamente a um dever, a uma obrigação, ao cumprimento de um contrato de trabalho no que se refere à assiduidade, responsabilidade, competência técnica, respeito, ética, aliados aos princípios constitucionais da administração pública, contidos no artigo 37 da Constituição Federal - legalidade, impessoalidade, moralidade, publicidade e eficiência.

Ocorre que, na atuação de alguns desses servidores, não se verifica o respeito a essas questões, parece que não compreendem que a contrapartida que lhes é exigida no contrato de trabalho é o zelo pelo bem público como "servidor" da sociedade e do bem público. Ao contrário, em muitos casos, observa-se a ênfase excessiva na obtenção de direitos trabalhistas, que converte o direito socialmente necessário em um conjunto de privilégios, por vezes, descabidos.

Esse tipo de conflito interfere e tem efeitos e impactos no modo como se dá o trabalho, no exercício cotidiano do trabalho, na atenção ao usuário e no projeto de trabalho da UBS. Percebe-se que, nesse tipo de conflito, os gerentes se encontram com escassa autonomia técnica para recompor a contratualidade prevista nem podem se apoiar nela para argumentar intersubjetivamente na coordenação dos processos 
de trabalho, ou seja, a coordenação tem pouco controle sobre esse tipo de conflito, e as medidas gerenciais instituídas (supervisão, advertência, transferência de unidade) têm tido pouco efeito, segundo os entrevistados.

O quarto grupo de conflito, tipificado como "problema pessoal ocorrido fora do trabalho", foi descrito por trabalhadores e coordenadores e envolveu dois trabalhadores, da mesma categoria profissional ou de categorias distintas. Apesar de ter ocorrido por motivos alheios ao trabalho, teve potência para adentrar o ambiente de trabalho e mobilizar outros trabalhadores, além dos envolvidos inicialmente, e provocar o conflito - o desentendimento, incluindo agressões verbais e até físicas, como exemplificado na fala de um coordenador: "Chegando à unidade, duas ACS haviam discutido e acabaram partindo pra agressão física. A equipe toda da unidade de saúde estava em tensão e cada um tomando seu partido" (C1).

Foi possível compreender que esse tipo de conflito adentra o ambiente de trabalho porque o cotidiano das unidades de saúde se constitui como espaço em que os trabalhadores de saúde estabelecem relações, se reconhecem e se estranham, e vão se conformando como sujeitos, com determinadas experiências vividas, pelas relações estabelecidas entre si e com outros atores desse cenário: outros trabalhadores, gestores e usuários. E é neste lugar que esses sujeitos compartilham experiências não só do trabalho, mas da vida social, ou seja, compartilham o mundo da vida.

Nessa tipologia, o desrespeito se situa na esfera das relações primárias (das relações amorosas e da amizade), afetando a autoconfiança daqueles que foram desrespeitados, provocando uma espécie de vergonha social 10. Nas situações relatadas, constata-se o rompimento do regime de validação da autenticidade expressiva, em que não se reconheceu que o parceiro de interação estava sendo autêntico e digno de confiança em suas ações e afirmações 9 .

O quinto tipo de conflito está relacionado à “assimetria entre os níveis de gestão" e, apesar de não ter sido narrado diretamente pelos participantes da pesquisa como conflito, houve várias manifestações dos coordenadores e trabalhadores e situações observadas que indicam que essa relação é permeada por tensão: a normatividade instituída que impede a paralisação do atendimento da unidade para reunião com a equipe; a falta de apoio da gestão intermediária às demandas da unidade; a relação assimétrica expressa pela ouvidoria e a fragmentação das ações demandadas por vários setores para serem desenvolvidas pela unidade de saúde. Essas situações apontaram que a normatividade técnica prevista no SUS para a execução do trabalho em uma UBS não coincide com as normas instituídas pela organização para regular o trabalho, o que provocou tensão constante entre os coordenadores para considerar ambas as normativas: a do SUS e a da gestão municipal. Houve referência de que, muitas vezes, repassam à unidade a responsabilidade pela implementação de ações que a gerência avalia não ter condições estruturais na unidade de desenvolvê-las de forma adequada; e mesmo assim "tem que fazer, muda toda sema$n a "$ (C10).

Os gerentes de UBS manifestaram o sentimento de desrespeito por parte do nível intermediário de gestão, acarretando consequências à sua estima social, na medida em que não sentiam sua atuação e contribuição pessoais reconhecidas como relevantes para a equipe gestora, da qual são integrantes. Essa situação pode comprometer a viabilidade do projeto institucional, uma vez que a solidariedade é um sentimento fundamental para que os objetivos que sejam comuns aos sujeitos em interação possam se tornar realizáveis 10 .

O último conflito tipificado está relacionado “à infraestrutura e à organização deficitária dos serviços do SUS" e compreende as condições estruturais do serviço: área física inadequada, falta de equipamentos, principalmente de informática, insuficiente oferta na atenção especializada e a forma como o trabalho está organizado. Esse tipo de conflito foi relatado por trabalhadores, coordenadores e também observado no cotidiano do trabalho, conforme explicitado por um trabalhador: "O serviço público tem esse nó. Então, grande parte das questões que vi com usuários foi o tempo de espera para o especialista, falta de alguns medicamentos, isso gera tensão porque é uma coisa que eu não sei quando isso vai acabar..." (T1).

Vários autores apontam que a dimensão física do acesso a outros níveis de complexidade do sistema de saúde é uma das condições para que haja garantia da integralidade da atenção no SUS 23,24 . No entanto, a articulação entre os níveis de atenção figura como ponto crítico a ser enfrentado pelo sistema de saúde na construção das redes de atenção. Essa dificuldade está relacionada a duas questões principais: a dificuldade da atenção básica à saúde se efetivar como coordenadora do cuidado nas redes de atenção 25 e a insuficiente oferta de serviços da média complexidade no âmbito do SUS, identificada pelos gestores como o "gargalo" e um dos principais obstáculos para a construção da integralidade da atenção 24 .

Outro fator que agrava a dificuldade de acesso à atenção na média e alta complexidade no 
SUS é a forma como a saúde é vista na atualidade: como um bem de consumo, consumo incentivado pela mídia. E, apesar de reconhecidos avanços tecnológicos, novos fármacos, procedimentos e equipamentos que contribuem no tratamento, nem sempre a indicação desses se dá com a prudência necessária a um bom resultado. Nesse sentido, a clássica análise de Donnangelo \& Pereira 26 sobre as práticas comunitárias de saúde no Brasil, da década de 1970, permanece atual, à medida que mostra que a medicalização da sociedade amplia as dificuldades da equipe de saúde em realizar o cuidado integral num contexto de infraestrutura deficitária em que os vários desconfortos são traduzidos como problemas de saúde para os quais há "certamente" um exame e um remédio "certeiros".

Nesse tipo de conflito, há um descompasso entre, de um lado, a normatividade técnica e jurídica presente na legislação que regulamenta o SUS, - em que a atenção básica é definida como a coordenadora do acesso e cuidado aos usuários nas redes de atenção, com vistas a garantir a integralidade da atenção à saúde -, e de outro lado, a normatividade contratualizada que rege a organização e o funcionamento dos serviços, limitados pelo financiamento insuficiente e frágil gestão, aliados à influência do modelo biomédico.

Essa situação gera conflito naqueles que se sentem desrespeitados por não terem seus direitos reconhecidos - tanto usuários quanto trabalhadores. Os primeiros pela não garantia do acesso aos serviços, necessários à integralidade da atenção, e os segundos pelas condições inadequadas de trabalho, expondo-os à revolta dos usuários pelo não atendimento de suas necessidades, já que são tidos pela população como representantes do SUS na UBS.

\section{Considerações finais}

O estudo demonstrou que o referencial teórico do processo de trabalho em saúde e as teorias do agir comunicativo e do reconhecimento, ao serem articulados, constituíram quadro teórico com potência explicativa e de compreensão do fenômeno estudado. Destaca-se a relevância do (não) reconhecimento mútuo, na perspectiva proposta por Axel Honneth 10, na interpretação da gênese e implicações práticas desses conflitos.

Os resultados apontam a convivência de distintas concepções de conflito entre coordenadores e trabalhadores e expressam a inserção desigual dos diferentes trabalhadores no processo de trabalho em saúde, em particular de trabalhadores de nível superior e de nível técnico.
Os conflitos foram interpretados como obstáculos que dificultam o exercício da contratualidade prevista nas relações cotidianas do trabalho, ou seja, o conflito se manifesta no descompasso entre o que está contratualizado e o modo como se dão as interações entre coordenadores e trabalhadores, e sua emergência provoca tensão ou até mesmo o rompimento dessa contratualidade no espaço institucional. O rompimento refere-se à expressão mais contundente do conflito, quando o que estava acordado deixa de ter vigência temporária, podendo se manifestar com discussões, desavenças, reações emocionais, sendo necessário, na maioria das vezes, que seja feita a mediação - uma ação comunicativa entre as partes envolvidas para que a contratualidade e a socialidade sejam restabelecidas.

As tensões e/ou o rompimento com a contratualidade prevista no cotidiano do trabalho estão relacionados a diversos aspectos em que reside a emergência dos conflitos, tipificados como: falta de colaboração entre os trabalhadores; o desrespeito pelo outro decorrente de relações assimétricas no ambiente de trabalho; o comportamento do "funcionário-problema" em que a postura e a atitude de alguns trabalhadores confrontam e extrapolam o horizonte normativo do SUS, da atenção básica à saúde e das relações de trabalho; problemas pessoais que tiveram potência para adentrar o ambiente de trabalho; relação assimétrica entre a UBS e outros níveis de gestão e ainda a infraestrutura e organização deficitárias dos serviços do SUS. Nessas circunstâncias, a ausência de reconhecimento refere-se principalmente às esferas do direito e da estima social, na perspectiva proposta por Honneth 10 .

Este estudo produziu conhecimentos sobre um tema com escassos estudos empíricos - o conflito no trabalho, especialmente aquele que se manifesta no espaço da atenção básica à saúde do SUS, porém se limitou a explicitar a existência de diferentes percepções sobre o conflito e apresentar uma tipologia para os conflitos mais frequentes nesse espaço. Tendo em vista a relevância do tema, especialmente para aqueles responsáveis pela gestão do trabalho no SUS, fazem-se necessários novos estudos, a fim de elucidar o problema e discutir tecnologias de resolução de conflitos no trabalho em saúde, especialmente na atenção básica à saúde. 


\section{Resumen}

Esta investigación analiza percepciones de conflicto por parte de trabajadores de unidades básicas de salud, basándose en un estudio de caso, de carácter comprensivo-interpretativo con un planteamiento crítico-hermenéutico. Los datos provienen de: un grupo focal formado por gerentes; observación del trabajo y entrevistas con trabajadores, realizadas de abril a noviembre 2011. Los resultados triangulados señalaron la coexistencia de distintas concepciones de conflicto. Se tipificaron seis modalidades: falta de colaboración en el trabajo; falta de respeto, debido a las relaciones asimétricas entre trabajadores; comportamiento del funcionario-problema; problemas personales; asimetría con otros niveles de gestión e infraestructura deficitaria de los servicios. Se destaca la relevancia del (no) reconocimiento mutuo, en la perspectiva propuesta por Axel Honneth, en la interpretación de la génesis y de las implicaciones prácticas de dichos conflictos.

Grupo de Atención al Paciente; Gerencia; Atención Primaria de Salud

\section{Colaboradores}

B. G. Carvalho participou da concepção e desenho do artigo, coleta, análise e interpretação dos dados, redação, revisão crítica de seu conteúdo e aprovação da versão final para publicação. M. Peduzzi e J. R. C. M. Ayres tiveram substancial contribuição na concepção e desenho do artigo, análise e interpretação dos dados, revisão crítica relevante do conteúdo intelectual do artigo e aprovação da versão final para publicação.

\section{Agradecimentos}

Agradecemos ao Programa de Pesquisa para o SUS: Gestão Compartilhada em Saúde (PPSUS) /Fundação Araucária pelo apoio financeiro à realização desta pesquisa (projetos 08/2009).

\section{Referências}

1. Cecílio LCO. É possível trabalhar o conflito como matéria-prima da gestão em saúde? Cad Saúde Pública 2005; 21:508-16.

2. Ciampone MHT, Kurcgant P. Gerenciamento de conflito e negociação. In: Kurcgant P, organizadora. Gerenciamento em enfermagem. Rio de Janeiro: Editora Guanabara Koogan; 2005. p. 54-65.

3. Ferreira $\mathrm{ABH}$. Mini Aurélio: o dicionário da língua portuguesa. 8a Ed. Curitiba: Positivo; 2010.

4. Boccato SBG. Como gerenciar um grupo em conflito. In: Malagutti W, Caetano KC, organizadores. Gestão do serviço de enfermagem no mundo globalizado. Rio de Janeiro: Rubio; 2009. p. 85-100.

5. Brown J, Lewis L, Ellis K, Stewart M, Freeman TR, Kasperski JM. Conflict on interprofessional primary health care teams - can it be resolved? J Interprof Care 2011; 25:4-10.
6. Corradi EM, Zgoda LTRW, Paul MFB. O gerenciamento de conflitos entre a equipe de enfermagem. Cogitare Enferm 2008; 13:184-93.

7. Long S. Primary health care team workshop: team members' perspectives. J Adv Nurs 1996; 23: 935-41.

8. Mendes-Gonçalves RB. Tecnologia e organização social das práticas de saúde: características tecnológicas do processo de trabalho na rede estadual de Centros de Saúde de São Paulo. São Paulo: Editora Hucitec/Rio de Janeiro: ABRASCO; 1994.

9. Habermas J. Teoría de la acción comunicativa: racionalidad de la acción y racionalización social. Madrid: Taurus; 2001.

10. Honneth A. Luta por reconhecimento: a gramática moral dos conflitos sociais. São Paulo: Editora 34; 2003. 
11. Ayres JRCM. Teoria do trabalho e construção de conhecimento em saúde coletiva: para uma epistemologia reconstruída como práxis emancipadora. Divulg Saúde Debate 1996; 14:13-6.

12. Pires D. Reestruturação produtiva e trabalho em saúde no Brasil. São Paulo: Annablume; 1998.

13. Peduzzi M. Mudanças tecnológicas e seu impacto no processo de trabalho em saúde. Trab Educ Saúde 2003; 1:75-91.

14. Merhy EE. Saúde: a cartografia do trabalho vivo. 3a Ed. São Paulo: Editora Hucitec; 2002.

15. Carvalho BG, Peduzzi M, Mandú ENT, Ayres JRCM. Work and inter-subjectivity: a theoretical reflection on its dialectics in the field of health and nursing. Rev Latinoam Enferm 2012; 20:19-26.

16. Miranda L, Rivera FJU, Artmann E. Trabalho em equipe interdisciplinar de saúde como um espaço de reconhecimento: contribuições da teoria de Axel Honneth. Physis (Rio J.) 2012; 22:1563-83.

17. Yin RK. Estudo de caso: planejamento e métodos. 4a Ed. Porto Alegre: Bookman; 2010.

18. Bosi MLM, Mercado FJ. Avaliação qualitativa de programas de saúde: enfoques emergentes. Petrópolis: Editora Vozes; 2006.

19. Triviños ANS. Introdução à pesquisa em ciências sociais: a pesquisa qualitativa em educação. São Paulo: Editora Atlas; 2007.
20. Ayres JRCM. Para comprender el sentido práctico de las acciones de salud: contribuciones de la herméutica filosófica. Salud Colect 2008; 4:159-72.

21. Cecílio LCO. A morte de Ivan Ilitch, de Leon Tolstói: elementos para se pensar as múltiplas dimensões da gestão do cuidado. Interface Comun Saúde Educ 2009; 13:545-55.

22. Farias LO, Vaitsman J. Interação e conflito entre categorias profissionais em organizações hospitalares públicas. Cad Saúde Pública 2002; 18:1229-41.

23. Conill EM. Avaliação da integralidade: conferindo sentido para os pactos na programação de metas dos sistemas municipais de saúde. Cad Saúde Pública 2004; 20:1417-23.

24. Spedo SM, Pinto NRS, Tanaka OY. O difícil acesso a serviços de média complexidade do SUS: o caso da cidade de São Paulo, Brasil. Physis (Rio J.) 2010; 20:953-72.

25. Cecilio LCO, Andreazza R, Carapinheiro G, Araújo EC, Oliveira LA, Andrade MGG et al. A atenção básica à saúde e a construção das redes temáticas de saúde: qual pode ser o seu papel? Ciênc Saúde Coletiva 2012; 17:2893-902.

26. Donnangelo MCF, Pereira L. Saúde e sociedade. São Paulo: Duas Cidades; 1976.

Recebido em 21/Jul/2013

Versão final reapresentada em 03/Dez/2013

Aprovado em 06/Jan/2014 